\title{
Unsatisfactory Knowledge, Attitude and Practice on Leptospirosis among Army Personnel's in Northeastern Malaysia
}

\author{
Siti Sara Y.1, Aziah B. D. ${ }^{2 *}$, Azwany Y. N. ${ }^{2}$, Mohd Nazri S. ${ }^{2}$, Zahiruddin W. M. ${ }^{2}$, Nabilah A. ${ }^{3}$, \\ Siti Asma' H. ${ }^{3}$, Zaliha I. ${ }^{4}$ \\ ${ }^{1}$ Public Health Division, Selangor State Health Department, Ministry of Health, Selangor, Malaysia \\ ${ }^{2}$ Department of Community Medicine, School of Medical Sciences, Universiti Sains Malaysia, Kelantan, Malaysia \\ ${ }^{3}$ Department of Medical Microbiology \& Parasitology, School of Medical Sciences, Universiti Sains Malaysia, Kelantan, Malaysia \\ ${ }^{4}$ Population Health \& Preventive Medicine Discipline, Faculty of Medicine, Universiti Teknologi MARA, Selangor, Malaysia \\ Email: *aziahkb@usm.my
}

How to cite this paper: Y., S.S., B. D., A., Y. N., A., S., M.N., M.W., Z., A., N., H., S.A. and I., Z. (2020) Unsatisfactory Knowledge, Attitude and Practice on Leptospirosis among Army Personnel's in Northeastern Malaysia. Health, 12, 281-292.

https://doi.org/10.4236/health.2020.123023

Received: February 12, 2020

Accepted: March 28, 2020

Published: March 31, 2020

Copyright $\odot 2020$ by author(s) and Scientific Research Publishing Inc. This work is licensed under the Creative Commons Attribution International License (CC BY 4.0).

http://creativecommons.org/licenses/by/4.0/

\section{(c) (i) Open Access}

\begin{abstract}
Leptospirosis is a re-emerging zoonotic disease caused by infection of the bacteria belongs to Genus leptospira. It occurs in tropical, subtropical and temperate zones. It is also known as occupational-related disease as certain occupations are associated with the occurrence of leptospirosis. Army is identified as one of the high-risk occupations in contracting leptospirosis. This study was done to determine knowledge, attitude and practice (KAP) among army personnel on leptospirosis. A cross sectional study was conducted among 616 army personnel in four based camps in Northeastern Malaysia, who fulfilled the inclusion and exclusion criteria. A validated KAP questionnaire was used, consisting of knowledge, attitude and practice questions. More than half (52.8\%) of the respondents had poor knowledge score. For the attitude score, almost the same proportions had satisfactory attitude. The same finding was seen in practice score, whereby those with good practice (54.9\%) and bad practice (45.9\%). In conclusion, the finding showed that almost all army personnel had unsatisfactory KAP, thus, it is recommended for the army to have a good health education program on leptospirosis among army personnel to protect the army personnel from risk of getting leptospirosis.
\end{abstract}

\section{Keywords}

Army Personnel, Leptospirosis, Knowledge, Attitude, Practice 


\section{Introduction}

Leptospirosis is presumed to be the most widespread re-emerging zoonotic disease in the world. The determinants of transmission of Leptospira infection include the presence of carrier animals, suitability of the environment for the survival of leptospires and interaction between man, animals and environment [1] [2].

Leptospirosis is a disease of global importance [3] [4] [5]. Pappas et al. (2008) stated that the most significant foci of the disease include the regions such as the Caribbean and Latin America, the Indian subcontinent, South East Asia, Oceania and Eastern Europe [2]. International Leptospirosis Society (ILS) surveys stated that there are currently 300,000 to 500,000 severe cases of leptospirosis globally. However the real number of cases is expected to be higher as there is lacking of surveillance program of leptospirosis worldwide [6]. It is highly prevalent in Asia Pacific region. However, the exposure varies between developed and developing countries [7]. A study done in Japan revealed that there was a difference between the pattern of leptospirosis in developed and developing countries [8].

Knowledge, attitude and practice (KAP) surveys are a common strategy done by researchers to gather the information on leptospirosis and to assess the safe work practice among populations at risk [9]. Researchers around the world especially those who are at the endemic region for leptospiral infections, had done various researches to assess the knowledge of the community and high-risk groups [10] [11] [12] [13] [14]. Unfortunately review of literature revealed that very little information regarding KAP study on leptospirosis among army personnel. This study presented the result of a study on KAP on leptospirosis among army personnel in Northeastern Malaysia. We hope that the findings from the study will provide a baseline data to assist policy makers in planning and developing appropriate strategies in prevention and control program in Malaysia, particularly involving the army personnel.

\section{Materials and Methods}

A cross sectional study was conducted in all the four army-based camps in Northeastern Malaysia. The objective was to assess their knowledge, attitude and practice on leptospirosis. The army personnel's knowledge, attitude and practice (KAP) were measured using a validated instrument (Knowledge, Attitude and Practice Questionnaire) [15]. There were a total of 67 questions in this questionnaire whereby 43 items were in knowledge domain, 12 items were in attitude domain while practice domain had 12 items. The knowledge questions represented seven constructs (causes, occupational risk groups, mode of transmissions, symptoms, complications, risk factors and prevention and control measures) while the attitude and practice questions corresponded to two constructs (positive attitude (off work) and positive attitude at workplace) and (safe work practice and general practice (off work)) respectively. For validity of the questionnaire, the overall Cronbach's alpha for all domains was 0.6 above, with knowl- 
edge domain had the highest Cronbach's alpha (0.912), followed by practise domain (0.611) and attitude domain (0.594).

This questionnaire started with the question of whether the respondents had ever heard about leptospirosis and the source that they heard that from. The sources of information were classified as television/radio, magazine, newspaper, health talk, doctor, poster/pamphlet and others. The term used was leptospirosis as the respondents were used to this term. The respondents that had heard of the disease could proceed to answer the rest of knowledge questions. Each knowledge item had three answer options. Each correct response was allocated 3 points, incorrect response was allocated 1 point while do know response was allocated 2 points. Questions on attitude were designed to be answered using Likert scale, which were Strongly agree, Agree, Not sure, Not agree, Strongly not agree. For positive attitude item, scores of "5", " 4 ", " 3 ", " 2 " and "1" were used for "Strongly agree", "Agree”, "Not sure”, "Not agree”, "Strongly not agree” respectively. For negative attitude, the above scoring was reversed. The information that was acquired is important in understanding the respondents' attitude in health seeking and use of preventive measures. The practice domain was also designed to be answered using Likert scales, which were "always", "often", "sometimes", "seldom" and "never". For good practice item, scores of " 5 ", “4”, “3”, "2" and "1" were used for "always", "often", "sometimes", "seldom" and "never" respectively. For bad practice, the scoring was reversed. The practice domain assessed the respondent's practice in term of safe work practice while they were at work as well as general practices while they were not at work. The practice domain was done to assess the practices of the respondents with regards to leptospirosis.

\section{Results}

All the eligible army personnel consented to participate in this study. All respondents were Malay males with the mean age of 29.2 (7.1) years old and ranged from 18 to 51 years old. The mean duration of employment was 11.5 (7.7) years. For level of education, 421 (68.3\%) of the respondents had received upper secondary school and above.

Most of the respondents have heard of leptospirosis (91.1\%). Of those who have ever heard of leptospirosis, majority of them (52\%) heard through either television or radio or both. The mean percentage score for knowledge was 74.00 (10.48). Based on that, 291 (47.2\%) of them were categorized as having good knowledge (Table 1).

Descriptive statistics of domain and sub domains of KAP scores were displayed in Table 2. Analysis for knowledge domain was done for those who have heard of leptospirosis $(n=561)$, whereas attitude and practice domains were analyzed for all the respondents $(n=616)$. For the knowledge domain, less than $80 \%$ of the respondents gave correct response in all subdomains. The lowest correct response percentage (19.4\%) demonstrated in knowledge sub domain was seen in subdomain complications. 
Table 1. Category of Knowledge, Attitude and Practice among army personnel in Northeastern Malaysia $(\mathrm{n}=616)$.

\begin{tabular}{ccc}
\hline Category & Frequency & $\%$ \\
\hline Army personnels' knowledge & & \\
Good (score $\geq 74 \%)$ & 291 & 47.2 \\
Poor (score $<$ 74\% or never heard about leptospirosis) & 325 & 52.8 \\
\hline Army personnels' attitude & & 50.8 \\
Satisfactory (score $\geq 88 \%)$ & 313 & 49.2 \\
Unsatisfactory (score $<88 \%)$ & 303 & \\
\hline Army personnels' practice & & 54.9 \\
Good (score $\geq 80 \%)$ & 338 & 45.1 \\
\hline Bad (score $<80 \%)$ & 278 & \\
\hline
\end{tabular}

Table 2. Descriptive statistics of correct answers given by the respondents.

\begin{tabular}{|c|c|c|}
\hline Domain & Sub domain & Correct response $\mathrm{n}(\%)$ \\
\hline \multirow{7}{*}{$\begin{array}{l}\text { Total knowledge among } \\
\text { ever heard }(\mathrm{n}=561)\end{array}$} & Causes & $433(70.3)$ \\
\hline & Occupational risk groups & $418(67.9)$ \\
\hline & Mode of transmissions & $277(45.0)$ \\
\hline & Symptoms & $228(37.1)$ \\
\hline & Complications & $120(19.4)$ \\
\hline & Risk factors & $236(38.2)$ \\
\hline & Prevention & $250(40.6)$ \\
\hline \multirow{2}{*}{ Total attitude $(n=616)$} & Positive attitude (off work) & $542(87.9)$ \\
\hline & Positive attitude at workplace & 499 (80.9) \\
\hline \multirow{2}{*}{ Total practice $(\mathrm{n}=616)$} & Safe work practice & $356(57.9)$ \\
\hline & General practice (off work) & $490(79.5)$ \\
\hline
\end{tabular}

For attitude domain, more than $80 \%$ of the respondents reported correct response in both subdomains, while for practice domain, less than $80 \%$ of the respondents gave correct responses in the two subdomains.

The analysis for each knowledge item was carried out only for those who had ever heard about leptospirosis $(\mathrm{n}=561)$. The mean score $(\mathrm{SD})$ and the percentage (\%) of correct answer for each item are displayed in Table 3.

Concerning attitudes towards leptospirosis, the respondents obtained a mean percentage score of $88 \%$ (12.69). The attitude towards leptospirosis was generally satisfactory as $50.8 \%$ of the respondents had satisfactory attitude score and $49.2 \%$ had unsatisfactory score (as in Table 1). Detailed analysis for each item is described in Table 4. 
Table 3. Knowledge Items with mean score (SD) and percentage (\%) of correct response $(\mathrm{n}=561)$.

\begin{tabular}{|c|c|c|c|}
\hline & Knowledge Items & Mean (SD) & $\begin{array}{c}\text { Correct } \\
\text { n (\%) }\end{array}$ \\
\hline \multicolumn{4}{|c|}{ CAUSES } \\
\hline 1. & Leptospirosis is a disease caused by microorganisms & $2.8(0.58)$ & $480(85.6)$ \\
\hline 2. & Leptospirosis is a zoonotic disease that can infect human & $2.8(0.51)$ & $498(88.8)$ \\
\hline 3. & Leptospirosis is an inherited disease & $2.8(0.54)$ & $459(81.8)$ \\
\hline 4. & Leptospirosis can be treated with antibiotics & $2.1(0.79)$ & $209(37.3)$ \\
\hline 5. & Leptospirosis can be diagnosed by blood investigations & $2.9(0.41)$ & $519(92.5)$ \\
\hline \multicolumn{4}{|c|}{ OCCUPATIONAL RISK GROUPS } \\
\hline 6. & Military & $2.8(0.55)$ & $474(84.5)$ \\
\hline 7. & Navy & $2.0(0.82)$ & $183(32.6)$ \\
\hline 8. & Air Force & $2.0(0.82)$ & $180(32.1)$ \\
\hline 9. & Police & $2.2(0.82)$ & $244(43.5)$ \\
\hline 10. & Fire brigade & $2.2(0.81)$ & $249(44.4)$ \\
\hline 11. & Rubber tapper & $2.5(0.73)$ & $384(68.4)$ \\
\hline 12. & Paddy planter & $2.6(0.70)$ & $411(73.3)$ \\
\hline 13. & Palm oil farmer & $2.6(0.70)$ & $410(73.1)$ \\
\hline \multicolumn{4}{|c|}{ MODE OF TRANSMISSIONS } \\
\hline 14. & Body cuts/wounds & $2.0(0.85)$ & $209(37.3)$ \\
\hline 15. & Contaminated food & $2.8(0.50)$ & $497(88.6)$ \\
\hline 16. & Mosquito bites & $1.7(0.81)$ & $125(22.3)$ \\
\hline \multicolumn{4}{|c|}{ SYMPTOMS } \\
\hline 17. & Muscle pain & $2.5(0.75)$ & $358(63.8)$ \\
\hline 18. & Fever with jaundice & $1.8(0.78)$ & $128(22.8)$ \\
\hline 19. & Fever & $2.6(0.67)$ & $422(75.2)$ \\
\hline 20. & Yellowish sclera & $2.1(0.80)$ & $212(37.8)$ \\
\hline 21. & Rashes & $1.9(0.78)$ & $153(27.3)$ \\
\hline 22. & Joint pain & $2.5(0.76)$ & $349(62.2)$ \\
\hline 23. & Hematemesis & $2.0(0.80)$ & $165(29.5)$ \\
\hline 24. & Asymptomatic & $1.4(0.62)$ & $40(7.1)$ \\
\hline \multicolumn{4}{|c|}{ COMPLICATIONS } \\
\hline 25. & Death & $2.8(0.55)$ & $484(86.3)$ \\
\hline 26. & Lung cancer & $1.8(0.77)$ & $125(22.3)$ \\
\hline 27. & Renal failure & $2.1(0.80)$ & $204(36.4)$ \\
\hline 28. & Liver damage & $2.1(0.80)$ & $207(36.9)$ \\
\hline 29. & Diabetes Mellitus & $1.5(0.62)$ & $36(6.4)$ \\
\hline 30. & Respiratory failure & $2.3(0.78)$ & $260(46.3)$ \\
\hline 31. & Meningitis & $1.9(0.74)$ & $130(23.2)$ \\
\hline
\end{tabular}




\section{Continued}

\section{RISK FACTORS}

\begin{tabular}{|c|c|c|c|}
\hline 32. & Eat while working & $1.8(0.89)$ & $180(32.1)$ \\
\hline 33. & Drink while working & $1.8(0.88)$ & $172(30.7)$ \\
\hline 34. & Smoke while working & $1.5(0.72)$ & $75(13.4)$ \\
\hline 35. & Drink from puddle & $2.6(0.73)$ & $412(73.4)$ \\
\hline 36. & Bathe in the river & $2.3(0.87)$ & $298(53.1)$ \\
\hline 37. & Use food container that being washed in the river & $2.2(0.87)$ & $276(49.2)$ \\
\hline \multicolumn{4}{|c|}{ PREVENTION } \\
\hline 38. & Bathing immediately after work & $2.5(0.80)$ & $386(68.8)$ \\
\hline 39. & $\begin{array}{l}\text { Maintaining the cleanliness of the house } \\
\text { and its surroundings }\end{array}$ & $2.7(0.71)$ & $451(80.4)$ \\
\hline 40. & Struggling with flood water & $1.6(0.80)$ & $113(20.1)$ \\
\hline 41. & Covering small cuts during work & $2.3(0.88)$ & $304(54.2)$ \\
\hline 42. & Quitting smoking & $1.7(0.82)$ & $132(23.5)$ \\
\hline 43. & Reducing sweet food intake & $1.7(0.80)$ & $115(20.5)$ \\
\hline
\end{tabular}

Table 4. Attitude Items with mean score (SD) and percentage (\%) of good attitude ( $\mathrm{n}=$ 616).

\begin{tabular}{|c|c|c|c|}
\hline \multicolumn{2}{|r|}{ Attitude items } & Mean (SD) & $\begin{array}{c}\text { Positive Attitude } \\
\mathrm{n}(\%)\end{array}$ \\
\hline \multicolumn{4}{|c|}{ GENERAL ATTITUDE (OFF WORK) } \\
\hline 1. & I need to know about leptospirosis & $4.7(0.53)$ & $605(98.2)$ \\
\hline 2. & I should make sure that my house is rats-free & $4.7(0.62)$ & $603(97.9)$ \\
\hline 3. & I do not care if my garbage bins have no cover & $4.6(0.90)$ & $566(91.9)$ \\
\hline 4. & I am not worried if I have to struggle with flood & $3.9(1.14)$ & $394(64.0)$ \\
\hline \multicolumn{4}{|c|}{ GENERAL ATTITUDE DURING OPERATION/TRAINING } \\
\hline 5. & $\begin{array}{l}\text { Drinking water from puddle } \\
\text { is not a problem for me }\end{array}$ & $4.5(0.98)$ & $521(84.6)$ \\
\hline 6. & Bathing in the river is not a problem for me & $3.4(1.29)$ & $281(45.6)$ \\
\hline 7. & Using water filter is troublesome for me & $4.3(1.10)$ & $482(78.2)$ \\
\hline 8. & I make sure that left over food is buried & $4.0(1.18)$ & $484(78.6)$ \\
\hline 9. & I need to see the paramedics if I have fever & $4.5(0.71)$ & $587(95.3)$ \\
\hline 10. & $\begin{array}{l}\text { I need to see the paramedics } \\
\text { if I have small wounds }\end{array}$ & $4.0(0.99)$ & $481(78.1)$ \\
\hline 11. & I do not mind if I see rats in the food storage area & $4.7(0.74)$ & $574(93.2)$ \\
\hline 12. & $\begin{array}{l}\text { I do not mind if I see the traces } \\
\text { of rats in the food storage area }\end{array}$ & $4.8(0.69)$ & $578(93.8)$ \\
\hline
\end{tabular}


The mean percentage score on preventive practices against leptospirosis was $80 \%$ (15.13). $54.9 \%$ of the respondents showed satisfactory practice score while $45.1 \%$ showed unsatisfactory score (as in Table 1). Table 5 shows the mean (SD) score for each item as well as the percentage of army personnel who adopted good practice at work and off work.

\section{Discussion}

Knowledge, attitude and practice questionnaire had been used as a tool to assess the safe work practice among population at risk [9] [11] [16]. Exploring the populations' knowledge, attitude and practice will help health professionals in understanding the workers' barriers to action, and factors that facilitate the adoption of recommended preventive actions.

In our study, there were a good percentage of respondents who have ever heard of leptospirosis. The same finding was seen in a study in Brazil whereby more than $90 \%$ of the respondents had heard of leptospirosis [14]. However, in contrast to our study, a study in Trinidad and Tobago among the household revealed that less than half of the respondents never heard of the disease [12]. Of those who ever heard of leptospirosis among our respondents, majority of them (52\%) heard through either television or radio or both. This was probably due to government response as well as media reports after few outbreaks occurred in Malaysia in 2007. Few outbreaks were reported among the trainees in National Service Camps, among the Bakun worker in Sarawak, and those who went for

Table 5. Practice Items with mean score (SD) and percentage (\%) of good practice $(\mathrm{n}=$ 616).

\begin{tabular}{|c|c|c|c|}
\hline \multicolumn{2}{|r|}{ Practice items } & Mean (SD) & $\frac{\text { Good practice }}{\mathrm{n}(\%)}$ \\
\hline \multicolumn{4}{|c|}{ SAFE WORK PRACTICE } \\
\hline 1. & I wash my hand before I go to sleep & $3.7(1.11)$ & $289(46.9)$ \\
\hline 2. & I wash my legs before I go to sleep & $4.0(1.09)$ & $381(61.9)$ \\
\hline 3. & I wash my hands before meals & $4.8(0.64)$ & $584(94.8)$ \\
\hline 4. & I use the water filter & $3.3(1.57)$ & $289(46.9)$ \\
\hline 5. & Fishing & $3.4(1.47)$ & $298(48.4)$ \\
\hline 6. & Bathing in the river & $3.4(1.38)$ & $345(56.0)$ \\
\hline 7. & Net fishing & $4.2(1.18)$ & $476(77.3)$ \\
\hline 8. & Animal hunting & $4.4(1.06)$ & $513(83.3)$ \\
\hline \multirow[t]{2}{*}{9.} & Bird hunting & $4.4(1.09)$ & $509(82.6)$ \\
\hline & GENERAL PRACTICE (OFF WORK) & & \\
\hline 10. & I ensure that my house is rats-free & $4.3(1.10)$ & $487(79.1)$ \\
\hline 11. & I struggle with flood water & $3.8(1.16)$ & $409(66.4)$ \\
\hline 12. & I store the food in a closed storage & $4.7(0.84)$ & $574(93.2)$ \\
\hline
\end{tabular}


recreational activities in Kedah, Penang and Sibu [17] [18] [19]. Leptospirosis was also included as notifiable disease by Ministry of Health starting from 2011 [20]. In annual report on leptospirosis in Queensland found that 52\% among leptospirosis cases had heard about the disease. From those who had ever heard of the disease, they reported that the main sources of information were from words of mouth, the poster, brochure and advertisements [21]. In the same report, the researchers noted that the higher risk groups in term of occupation had better awareness of leptospirosis amongst cases than other patient.

In another study among town service workers whom were considered as high risk occupational group, in contrast to our study, there were a low percentage of respondents who ever heard of leptospirosis, which was only $12.8 \%$ of them had ever heard of the disease [9]. Meanwhile, another study done among high risk occupational group; the butchers and their assistants in slaughterhouses, it was reported that $78.2 \%$ of them had heard of the disease [11]. From those who had heard of the disease, majority of them heard it from the media and public health inspectors [11].

All the sub domains in knowledge domain were less than $80 \%$, indicating that there was a need for health education on leptospirosis among the respondents. The weakest area of knowledge identified in our study was in the "complications" sub domain whereby only $19.4 \%$ of the respondents gave the correct answer in this sub domain and it was noted that there were some of the respondents who got only $25 \%$ score. Knowing the "complications", the respondents will be aware and help to recognize the severity of leptospirosis at an early stage, thus can help in proper treatment and case management, which can save lives. The second lowest sub domain in knowledge domain was "symptoms" sub domain. Among all the respondents, only $37.1 \%$ gave the correct response. This finding indicated that majority of them were not aware of having the disease as most of infected person were asymptomatic. Furthermore, our respondents were healthy and asymptomatic at the time of data collection.

The other sub domain with less than $40 \%$ of correct response given by the respondents was the "risk factor" sub domain. Knowing the "risk factors", the workers will be more aware about the disease and will have some information on how to avoid or prevent any practice that can predispose them to leptospirosis. This could motivate them to practice good work practice. For "prevention" and "mode of transmission" sub domains, the respondents gave $40.6 \%$ and $45 \%$ correct response respectively. Knowledge on "causes" and "occupational risk groups" was relatively better compared to the other sub domains, implying that the workers knew that leptospirosis was caused by microorganisms and was related to rats' urine, but they had little knowledge on factors that contributed to the disease. The finding in our study was contradict to a study in Brazil, which more than two-thirds of respondents correctly identified the modes of disease transmission and ways to reduce exposure [14].

It was an interesting fact that majority of the respondents who ever heard about leptospirosis had false belief that leptospirosis can be transmitted through 
mosquito bites and it can cause Diabetes Mellitus. The other important fact was majority of them gave the incorrect response for cuts and wounds on the body as one of the modes of transmission in leptospirosis. This was a very important false belief that needs to be corrected as this factor was commonly seen in this group. This wrong belief might spread to the other army personnel and subsequently to the community, thus leading to poor disease control and prevention, especially in high risk occupational group as in our study.

Generally, the respondents had positive attitude whereby $87.8 \%$ of the respondents had positive attitude when they were off work. However, the positive attitude at workplace was lower than their positive attitude while they were off work whereby $80.9 \%$ of the respondents reported positive attitude at workplace. The important area that was identified as considering higher risk attitude while the respondents were not at work was high risk was attitude on struggling with flood water. Positive attitude at workplace which were considered important include the high-risk attitude during operation or training sessions which include bathing in the river, the needs to see the paramedics when they had wounds or cuts and the burial of leftover food. The finding was consistent with the low correct response given for "risk factors" and "mode of transmission" in knowledge sections. The other interesting fact was that the relation of knowledge on the wound and cuts during work with the attitude towards health seeking behavior related to the cuts and wounds when they were at work. The respondents reported low percentage of correct response in knowledge section thus was translated into their attitude as well. Even though the respondents might be aware of leptospirosis, they were still challenging and obstacles in convincing people to take all the safety precautions. The same result was seen in a study Thailand [22]. The people could be knowledgeable about certain disease, but it was not easy to change the attitude and practice of the people as seen in attitude towards smoking. In comparison to attitude, we found lower percentage of correct response for good practice score among the respondents. Only $57.9 \%$ of the respondents had safe work practice while $79.5 \%$ reported correct response for general practice off work. This was probably due to the respondents were unable to understand the benefit of given behaviors regardless of the understanding. The weakest area identified in safe work practice sub domain was related to personal hygiene, which was covered by item that related to hand washing before sleeping and bathing in the river. Previous study also shared the same finding as our study whereby the respondents weakest area was related to personal hygiene [12]. For the general practice off work, the weakest area identified was struggling with flood water. This was consistent with the finding in the attitude domain as well. Flooding is a common problem in this area in Malaysia; therefore, it might be perceived that it is not a dangerous practice.

Evidently, the respondents in this study reported correct response for good attitude and practice. Most of them had heard of the disease; however certain points revealed that there was some misunderstanding in their knowledge. That 
might be the reason why it was not translated into good attitude and practice. The seroprevalence of leptospirosis was also high among the respondents indicating that might be some flaws in preventive measures. The possible reason might be because of the nature of their job in which they need to follow orders and could not ask for any explanations and reasons for any order if it comes from the superior. This factor might contribute for making them unsure and unclear about the reason of their attitude and practice. There might be many other factors hindering such as perceived benefits, motivational drive, social factors and taboo. Further studies should actively look for the factors avoiding preventive practice of leptospirosis as behavior depends on many other factors beside knowledge and attitude. A surprising finding by a study in Trinidad and Tobago done involving 800 households showed that there was a positive attitude towards general health and good sanitary practices among them, although there was also a lack of knowledge of leptospirosis [12]. This finding was contradicted to the finding in our study.

Our study established an exciting pattern in the knowledge, attitude as well as practice of the high-risk group respondents in this highly prevalent area with leptospirosis and hint at the shortcomings of the control program. Identified weakness was found in the knowledge section that also may affect the attitude and practice level. The findings of this study at this point of time warrant the needs of health education among army personnel; should be improved if it was already present and special attention is needed. This is important as the army personnel tend to be busy with the operation and military exercise, thus a simple and short duration program is more suitable for them. A longer training or program would be less suitable and less likely to be used. Previous studies also identified the importance of awareness campaign as factors that can contribute to improving the knowledge and should not be disregarded [10] [22].

\section{Conclusion}

Knowledge, attitude as well as in practice of the army personnel in this highly prevalent area showed an interesting pattern and reflect the shortcomings at the control and preventive measures. Weaknesses detected in the knowledge section that affects the attitude and the practice. The information gathered can be used to develop and plan for control and preventive program of leptospirosis targeted specifically at army personnel.

\section{Acknowledgements}

The authors would like to acknowledge Universiti Sains Malaysia (USM) for awarding Research University Grant (1001/PPSP/812106). Special thanks to the Research and Ethics Committee (Human) USM for reviewing and approving the study. We would like to acknowledge to the Medical Division Army who gave the permission for this research and all the respondents for this study from all the four army camps, who provided us their valuable response and cooperation in this study. 


\section{Conflicts of Interest}

The authors declare no conflicts of interest regarding the publication of this paper.

\section{References}

[1] Sehgal, S.C. (2006) Epidemiological Patterns of Leptospirosis. Indian Journal of Medical Microbiology, 24, 310-311. https://doi.org/10.4103/0255-0857.29405

[2] Pappas, G., Papadimitriou, P., Siozopoulou, V., Christou, L. and Akritidis, N. (2008) The Globalization of Leptospirosis: Worldwide Incidence Trends. International Journal of Infectious Diseases, 12, 351-357.

https://doi.org/10.1016/j.ijid.2007.09.011

[3] Johnson, M.A., Smith, H., Joeph, P., Gilman, R.H., Bautista, C.T., Campos, K.J., Cespedes, M., Klatsky, P., Vidal, C., Terry, H., Calderon, M.M., Coral, C., Cabrera, L., Parmar, P.S. and Vinetz, J.M. (2004) Environmental Exposure and Leptospirosis, Peru. Emerging Infectious Diseases Journal, 10, 1016-1022. https://doi.org/10.3201/eid1006.030660

[4] Cachay, E.R. and Vinetz, J.M. (2005) A Global Research Agenda for Leptospirosis. Journal of Postgraduate Medicine, 51, 174-178.

[5] Jansen, A., Schoneberg, I., Frank, C., Alpers, K., Schneider, T. and Stark, K. (2005) Leptospirosis in Germany, 1962-2003. Emerging Infectious Diseases, 11, 1048-1054. https://doi.org/10.3201/eid1107.041172

[6] Hartskeerl, R.A. (2006) Leptospirosis: Current Status and Future Trends. Indian Journal of Medical Microbiology, 24, 309. https://doi.org/10.4103/0255-0857.29404

[7] Victoriano, A.F., Smythe, L.D., Gloriani-Barzaga, N., Cavinta, L.L., Kasai, T., Limpakarnjanarat, K., Ong, B.L., Gongal, G., Hall, J., Coulombe, C.A., Yanagihara, Y., Yoshida, S. and Adler, B. (2009) Leptospirosis in the Asia Pacific Region. BMC Infectious Diseases, 9, 147. https://doi.org/10.1186/1471-2334-9-147

[8] Yanagihara, Y., Villanueva, S.Y., Yoshida, S., Okamoto, Y. and Masuzawa, T. (2007) Current Status of Leptospirosis in Japan and Philippines. Comparative Immunology, Microbiology \& Infectious Diseases, 30, 399-413.

https://doi.org/10.1016/j.cimid.2007.05.003

[9] Rahim, S.M., Aziah, B.D., Nazri, S.M., Azwany, Y.N., Habsah, H., Zahiruddin, W.M., Zaliha, I. and Rusli, A.M. (2011) Town Service Workers' Knowledge, Attitude and Practice towards Leptospirosis. Brunei Darussalam Journal of Health, 5, 12.

[10] Emanuel, S., Swai, L.S. and Daborn, C. (2010) Knowledge and Attitude towards Zoonoses among Animal Health Workers and Livestock Keepers in Arusha and Tanga, Tanzania. Tanzania Journal of Health Research, 12, 280-286. https://doi.org/10.4314/thrb.v12i4.54709

[11] Brown, P.D., McKenzie, M., Pinnock, M. and McGrowder, D. (2011) Environmental Risk Factors Associated with Leptospirosis among Butchers and Their Associates in Jamaica. The International Journal of Occupational and Environmental Medicine, 2, 47-57.

[12] Mohan, A.R.M. and Chadee, D.D. (2011) Knowledge, Attitudes and Practices of Trinidadian Households Regarding Leptospirosis and Related Matters. International Health, 3, 131-137. https://doi.org/10.1016/j.inhe.2011.03.002

[13] Acosta, R. (2012) Intensify Campaigns against Leptospirosis, Study Says. 
[14] Navegantes de Araujo, W., Finkmoore, B., Ribeiro, G.S., Reis, R.B., Felzemburgh, R.D., Hagan, J.E., Reis, M.G., Ko, A.I. and Costa, F. (2013) Knowledge, Attitudes, and Practices Related to Leptospirosis among Urban Slum Residents in Brazil. American Journal of Tropical Medicine and Hygiene, 88, 359-363. https://doi.org/10.4269/ajtmh.2012.12-0245

[15] Raisuddin, N.S. (2009) Validation of Knowledge, Attitude and Practice (KAP) Questionairre among Army Personnel in Terengganu, Universiti Sains Malaysia, Kubang Kerian.

[16] May-Taffe, K. (2006) The Knowledge, Attitudes and Practices of Leptospirosis Infection among Public Health Inspectors in the Kingston and St. Andrew Region. University of West Indies, Jamaica.

[17] Anonymus (2008) Summary of Current Leptospirosis Outbreaks in Malaysia. http://www.flutrackers.com/forum/showthread.php?t=150283

[18] Vinod, G. (2012) Another Death at National Service Camp. http://www.freemalaysiatoday.com/category/nation/2012/03/13/another-death-at-n ational-service-camp/

[19] Teoh, S. (2012) National Service Camp Closed over Leptospirosis Risk. http://www.themalaysianinsider.com/malaysia/article/national-service-camp-closed -over-leptospirosis-risk/

[20] Ministry of Health (2011) Guidelines for the Diagnosis, Management, Prevention and Control of Leptospirosis in Malaysia.

[21] Robertson, H., Hanna, J. and Brookes, D. (2002) Leptospirosis Annual Report 2002. Tropical Public Health Unit Network, Queensland.

[22] Chomphookhao, C. (2010) Leptospirosis Prevention Behaviours of Leptospirosis Patient in Epidemic Area of Kalasin Province, Bangkok. 